\title{
The radiocarbon age of organic carbon in marine surface sediments
}

Department of Marine Chemistry and Geochemistry, Woods Hole Oceanographic Institution, Woods Hole, MA 02543, USA

20 Keywords: Radiocarbon, C-14, Organic Carbon, Marine Sediments, Box Model, Global Carbon Cycle 


\section{Abstract}

Long-term carbon cycling and climate change are strongly dependent on organic carbon (OC) burial in marine sediments. Radiocarbon $\left({ }^{14} \mathrm{C}\right)$ has been widely used to constrain the

25 sources, sinks, and processing of sedimentary OC. To elucidate the dominant controls on the radiocarbon content of total organic carbon $\left({ }^{14} \mathrm{C}_{\mathrm{TOC}}\right)$ accumulating in surface sediments we construct a box model that predicts ${ }^{14} \mathrm{C}_{\mathrm{TOC}}$ in the sediment mixed layer (measured as fraction modern, Fm). Our model defines three distinct OC pools (“degradable," "semi-labile," and "refractory") and assumes that ${ }^{14} \mathrm{C}_{\mathrm{TOC}}$ flux to sediments is exclusively derived from surface

30 ocean primary productivity, and hence follows a "generic" surface ocean dissolved inorganic carbon (DIC) bomb curve. Model predictions are compared to a set of 75 surface sediment samples, which span a wide geographic range and reflect diverse water column and depositional conditions, and for which sedimentation rate and mixed layer depth are well characterized. Our model overestimates the Fm value for a majority (65\%) of these sites, especially at shallow water

35 depths and for sites characterized by depleted $\delta^{13} \mathrm{C}_{\mathrm{TOC}}$ values. The model is most sensitive to sedimentation rate and mixed-layer depth. Therefore, slight changes to these parameters can lead to a match between modeled and measured Fm values at many sites. Because of model sensitivity, slight changes in sedimentation rate and mixed layer depth can allow predictions to match measured Fm at many sites. Yet, in some cases, we find that measured Fm values cannot

40 be simulated without large and unrealistic changes to sedimentation rate and mixed layer depth. These results point to sources of pre-aged OC to surface sediments and implicate soil-derived terrestrial OC, reworked marine OC, and/or anthropogenic carbon as important components of the organic matter present in surface sediments. This approach provides a valuable framework 
within which to explore controls on sedimentary organic matter composition and carbon burial 45 over a range of spatial and temporal scales. 


\section{INTRODUCTION}

Organic carbon $(\mathrm{OC})$ burial in marine sediments represents an important sink for carbon

50 on geological time scales. The dynamics and magnitude of $\mathrm{OC}$ burial are closely linked to atmospheric oxygen concentrations and the cycling of both major and minor elements, and thus have important implications for atmospheric carbon dioxide and its role in climate variability (Berner, 1982; Hedges and Keil, 1995; Burdige, 2007). Many studies have sought to clarify the sources, sinks, and controls on OC processing and burial. Yet significant gaps remain in our

55 understanding of the factors that determine global variations in the content and characteristics of organic matter accumulating in marine sediments (Eglinton and Repeta, 2003). A well-cited synthesis of spatial variations in marine surface sediment OC content highlighted the importance of continental margins in organic matter burial (Premuzic et al., 1982). However, we lack similar information on the origin of the OC buried in these environments. Indeed, while $\sim 90 \%$ of OC

60 burial occurs in deltaic and margin settings that are strongly influenced by processes on the adjacent continents (Hedges and Keil, 1995), the fate of terrestrial OC in the coastal ocean remains unclear (Hedges et al., 1997; Burdige, 2005). The present study examines this problem by constructing a model that predicts the radiocarbon content of total organic carbon $\left({ }^{14} \mathrm{C}_{\mathrm{TOC}}\right)$ in the sediment mixed layer, and by comparing modeled predictions to the observed distribution of

$65{ }^{14} \mathrm{C}_{\mathrm{TOC}}$ in marine surface sediments.

Understanding how OC burial varies over space and time requires knowledge of major sources, sinks, and transformations. Yet the origin of the organic matter that is buried within continental margin sediments represents one of the long-standing questions in marine geochemistry. This question has been difficult to resolve because of myriad sources, the 
70 complex sedimentological and biogeochemical processes at work, and our limited ability to structurally characterize and assign provenance to the bulk of organic materials present (Lee et al., 2004).

Particulate OC arriving at the sediment surface has several possible sources, including particles that rain down from the surface ocean as part of the marine "biological pump,"

75 terrestrial particles delivered via rivers and wind, and reworked sedimentary particles from resuspension events, down-slope sloughing, or other lateral transport processes. There is also a large body of evidence suggesting that $\mathrm{OC}$ is highly attenuated and degraded in transit to marine sediments by microbes in soils, rivers, estuaries, and the marine water column (Hedges and Oades, 1997; Hedges et al., 1997; Lee et al., 1998; Lee et al., 2004). During its protracted residence in the marine sedimentary mixed layer, OC may be oxidized completely to carbon dioxide, transformed into new organic compounds by benthic fauna and microbes, altered by physical and chemical processes, or buried without alteration. There is evidence that sedimentary OC contains components with a range of reactivity determined by source composition and diagenetic processing (Westrich and Berner, 1984;

85 Middelburg, 1989). Likewise, environmental factors such as oxygen penetration depth, mineral associations, benthic community composition, and bottom currents would be expected to exert some control on the fate of OC (Mayer, 1994; Sayles et al., 1994; Hedges and Keil, 1995; Hartnett et al., 1998). The magnitude of different inputs as well as the rates of these processes strongly influence the fate of $\mathrm{OC}$ in sediments, and have clear implications for

90 paleoceanographic reconstructions (see Ohkouchi et al., 2002; Zonneveld et al., 2010) as well as for the global carbon cycle. Yet our ability to predict which inputs and processes dominate at specific times and locations in the ocean remains rudimentary. 
Oceanographers have developed and applied a suite of sophisticated geochemical tools to characterize the source and fate of OC in marine sediments. These include, among others,

95 measurements of $\mathrm{OC} / \mathrm{N}$ ratios, stable carbon isotopes $\left({ }^{12} \mathrm{C},{ }^{13} \mathrm{C}\right)$, and the abundance and isotopic composition of biomarker compounds reflecting both terrestrial (e.g., plant wax $n$-alkanes, lignin phenols) and marine algal (e.g., phytoplankton sterols, haptophyte-derived alkenones) inputs. For example, numerous studies have shown that $\delta^{13} \mathrm{C}$ values for sedimentary $\mathrm{OC}$ increase along river to ocean transects (e.g., Gearing et al., 1977; Prahl et al., 1994), suggesting terrestrial carbon

100 removal. These tools have helped clarify marine OC dynamics but are often limited by ambiguous or non-representative signatures, narrow geographic scope, environmental heterogeneity, and non-conservative behavior. For example, a typical $\delta^{13} \mathrm{C}_{\mathrm{TOC}}$ value for sediments on the Northwest African margin (-20\%) could point to a dominant marine OC source or may simply reflect a 50:50 mixture of terrestrial $\mathrm{C}_{3}(\sim-27 \%)$ and $\mathrm{C}_{4}(\sim-13 \%)$ plant derived

105 OC from the adjacent continent. Interpretations based on elemental ratios, including $\mathrm{OC} / \mathrm{N}$ and $\mathrm{OC} / \mathrm{P}$, may be confounded by poorly defined end-members and/or the differential degradation of certain biochemicals (Ruttenberg and Goni, 1997). And although biomarker compounds are highly source-specific, they tend to occur in trace concentrations, so inferences about overall OC content are difficult to make. Thus, there is significant uncertainty associated with each of these 110 approaches for apportioning marine and terrestrial organic matter $(\mathrm{OM})$ sources.

Radiocarbon $\left({ }^{14} \mathrm{C}\right)$ adds an additional layer of specificity, and has been used together with ${ }^{13} \mathrm{C}$ to more fully constrain OC sources (Wang and Druffel, 2001; Blair et al., 2003; Nagao et al., 2005; Drenzek et al., 2007). While dual isotope approaches may still be ambiguous, radiocarbon has the potential to constrain OC sources and transport timescales. For example, radiocarbon 115 measurements have provided some of the strongest evidence for the presence of petrogenic 
(fossil) OC in marine sediments (Dickens et al., 2004; Galy et al., 2007b). Studies of the radiocarbon content of terrestrial biomarkers have also shed light on the lifetime of terrestrial OC prior to deposition in ocean margin sediments (Eglinton et al., 1997; Eglinton et al., 2002; Ohkouchi et al., 2003; Drenzek et al., 2009). Multiple-tracer approaches improve our ability to assign sedimentary OC sources and transport timescales, but these studies are time-consuming, expensive, and difficult to execute on a large scale.

The purpose of the present study is to examine the distribution of ${ }^{14} \mathrm{C}_{\mathrm{TOC}}$ in a broad range of continental margin surface sediments (Figs. 1 and 2). Throughout this paper we express ${ }^{14} \mathrm{C}_{\mathrm{TOC}}$ content as fraction modern (Fm), where large $\mathrm{Fm}$ values correspond to young ${ }^{14} \mathrm{C}$ ages. In

125 Fig. 2, Fm values generally decrease with increasing water depth, although considerable variability is evident, especially at shallow water depths. We investigate this relationship by comparing observations to box model predictions of ${ }^{14} \mathrm{C}_{\mathrm{TOC}}$ content in the sediment mixed layer. Our model (wrongly) assumes that the only source of OC to sediments is from contemporaneous marine surface ocean primary productivity and therefore reflects the radiocarbon content of

130 dissolved inorganic carbon (DIC) in surface waters. In the past, differences between the modeled and actual radiocarbon content of surface sediments from the northeastern Pacific and the Middle Atlantic Bight have been used to suggest sources of pre-aged OC (Anderson et al., 1988; Hwang et al., 2005). When given global reach, this approach has the potential to identify dominant factors controlling surface sediment ${ }^{14} \mathrm{C}_{\mathrm{TOC}}$ and also highlight regions where further, in-depth 135 geochemical and sedimentological studies would be appropriate and cost-effective.

\section{METHODS}




\subsection{Database Construction}

A database of 326 core-top Fm values was compiled from existing literature and our own previously unpublished data (see electronic annexes EA-1 and EA-3). Ancillary data for each sample (\%TOC, $\delta^{13} \mathrm{C}_{\mathrm{TOC}}$, sedimentation rate, and mixed layer depth) were included in the database when available. Most samples are the $0-1 \mathrm{~cm}$ section of cores collected with a multicorer or box corer. While the depth interval of some other samples differed from $0-1 \mathrm{~cm}$, all

145 samples were obtained from the sedimentary mixed layer as defined below. Ocean margin sites dominate the database, but abyssal ocean and estuarine regimes are also represented (Fig. 1). Our modeling effort (described below) focuses on a subset of 75 sites for which Fm values are accompanied by measurements of sedimentation rate and mixed layer depth, which range from $0.075-425 \mathrm{~cm} \mathrm{ky}^{-1}$ and $0.1-27 \mathrm{~cm}$, respectively ("Subset 1"). The data for this subset,

150 including all of the available ancillary information and literature references are presented in electronic annexes EA-2 and EA-3.

\subsubsection{Case Study: ${ }^{14} C_{T O C}$ in NW African Margin sediments}

The database includes 24 core-tops from the NW African margin that were collected in July 2007. The top $0-1 \mathrm{~cm}$ of each multi-core was isolated and stored frozen in pre-combusted

155 glass jars before being freeze-dried, then crushed and homogenized with a mortar and pestle.

These samples were analyzed for ${ }^{14} \mathrm{C}$ at the National Ocean Sciences Accelerator Mass Spectrometry (NOSAMS) facility at the Woods Hole Oceanographic Institution. At NOSAMS, inorganic carbon was removed with $10 \% \mathrm{HCl}$ (Trace Metal Grade) at $60{ }^{\circ} \mathrm{C}$. The solids remaining after acid treatment were rinsed with distilled water and dried. Each sample was then 160 combusted to $\mathrm{CO}_{2}$, converted to graphite, and analyzed by AMS to determine a ${ }^{14} \mathrm{C} /{ }^{12} \mathrm{C}$ ratio. 
Measured ${ }^{14} \mathrm{C}$ values are expressed according to convention (Stuiver and Polach, 1977; Stuiver, 1980) and all ${ }^{14} \mathrm{C}_{\mathrm{TOC}}$ values have been corrected for decay since collection.

\subsubsection{Sources of error in ${ }^{14} C_{\text {TOC }}$ measurements}

The average instrumental error for the 75 cores of Subset 1 is 0.005 Fm units. Also, when

165 measuring OC isotopes, the acidification method used to remove inorganic carbon may introduce bias. This can stem from incomplete removal of recalcitrant carbonate minerals such as dolomite (Galy et al., 2007a). Conversely, more aggressive methods may preferentially remove ${ }^{14} \mathrm{C}$ - (and ${ }^{13} \mathrm{C}$-) enriched labile organic matter, and lead to fractionations in ${ }^{14} \mathrm{C}$ on the order of 0.005 to 0.01 Fm units (Komada et al., 2008 and references therein). In both cases, non-optimal

170 acidification methods would bias our measured Fm values towards smaller values (older ${ }^{14} \mathrm{C}$ ages). However, these errors are considered to be small when compared to the overall range of measured Fm values in Subset 1 (0.251 to 1.015).

\subsection{Mixed Layer OC Model}

A schematic of our model of marine surface sediment OC is shown in Fig. 3. Similar to Emerson et al. (1987), we assume a homogeneous mixed layer, but whereas the Emerson model used one component of OC, our model uses three components of varying reactivity. Thus, the model consists of six equations: ${ }^{12} \mathrm{C}$ and ${ }^{14} \mathrm{C}$ in each of the three $\mathrm{OC}$ fractions. Because of the possible significance of bomb ${ }^{14} \mathrm{C}$ in the mixed layer, the model includes a time-varying flux of

${ }^{14} \mathrm{C}_{\mathrm{TOC}}$ to the sea floor. The general, governing equation for the radiocarbon in the $\mathrm{OC}$ fraction is:

$$
\frac{d C_{i}}{d t}=\frac{F_{i}(t)}{h}-\left(\lambda+k_{i}\right) C_{i}-\frac{s C_{i}}{h}
$$

$C_{i}$ is the concentration of each component of OC ( $\mathrm{i}=$ degradable, semi-labile, or refractory $)$ and $F_{i}$ is the flux of that component to the sea floor. $\lambda$ is the radioactive decay constant for ${ }^{14} \mathrm{C}(1.21$ 
$\left.\mathrm{x} 10^{-4} \mathrm{y}^{-1}\right), \mathrm{s}$ is the sedimentation rate $\left(\mathrm{cm} \mathrm{y}^{-1}\right)$ and $h$ is mixed layer depth $(\mathrm{cm})$. The equation for

$185{ }^{12} \mathrm{C}$ in fraction $i$ is the same as (1), but without the radioactive decay term. We have neglected ${ }^{13} \mathrm{C}$ in these equations, thus the total $\mathrm{OC}$ in fraction $i$ is the sum of ${ }^{12} \mathrm{C}$ and ${ }^{14} \mathrm{C}$. We assume that there is a constant flux of total OM (from surface ocean productivity) with a variable flux of ${ }^{14} \mathrm{C}$ that is described by a representative ${ }^{14} \mathrm{C}$ vs. time curve, determined by measurements of corals (Guilderson et al., 2004). "Degradable" OC was assumed to be $90 \%$ of the flux to the sea floor 190 with an assigned decay constant $\left(k_{\mathrm{D}}\right)$ of $1 \mathrm{y}^{-1}$; "semi-labile" $\left(k_{\mathrm{SL}}=0.04 \mathrm{y}^{-1}\right)$ and "refractory" $\left(k_{\mathrm{R}}=\right.$ 0) components were each assumed to be $5 \%$ of the flux (Soetaert et al., 1996; Sayles et al., 2001). We also assume that the three OC fractions have the same age upon deposition into the surface sediment mixed layer. A single value for the flux of total OC to the sea floor (flux12cTOT) of $40 \mu \mathrm{mol} \mathrm{C} \mathrm{cm}{ }^{-2} \mathrm{y}^{-1}$ was used (Reimers et al., 1992; Lohse et al., 1998; Martin 195 and Sayles, 2004). Initial values for $C_{i}(a t t=0$, corresponding to the year 1950) were derived from a steady-state solution to the governing equation assuming the flux had a constant prebomb Fm value $\left(\mathrm{Fm}_{\text {pre-bomb }}=0.95\right)$. The governing equation was solved in MATLAB at $0.1 \mathrm{y}$ intervals using the ordinary differential equation solver ode15s, and modeled OC concentrations were recorded for the year each sample was collected. The ${ }^{14} \mathrm{C}$ content of mixed-layer (“"ml”)

200 TOC was then calculated by:

$$
\left(\frac{{ }^{14} \mathrm{C}}{{ }^{12} \mathrm{C}}\right)_{\mathrm{ml}}=\frac{{ }^{14} \mathrm{C}_{\mathrm{D}}+{ }^{14} \mathrm{C}_{\mathrm{SL}}+{ }^{12} \mathrm{C}_{\mathrm{R}}}{{ }^{12}+{ }^{12} \mathrm{C}_{\mathrm{SL}}+{ }^{12} \mathrm{C}_{\mathrm{R}}}
$$

This ${ }^{14} \mathrm{C} /{ }^{12} \mathrm{C}$ ratio is then converted to a fraction modern (Fm) value:

$$
\mathrm{Fm}=\left[\frac{\left({ }^{14} \mathrm{C} /{ }^{12} \mathrm{C}\right)_{\mathrm{ml}}}{\left({ }^{14} \mathrm{C} /{ }^{12} \mathrm{C}\right)_{\text {"modern" ref }}}\right]
$$

where the "modern" reference is 0.95 times the specific activity of NBS Oxalic Acid I, 205 normalized to a $\delta^{13} \mathrm{C}_{\mathrm{VPDB}}$ of $-19 \%$ (Stuiver and Polach, 1977). Accordingly, the denominator in 
equation (3) is equal to $1.176 \times 10^{-12}$ (Karlen et al., 1968). We do not further normalize modeled Fm values to a $\delta^{13} \mathrm{C}_{\mathrm{VPDB}}$ of $-25 \%$ because this correction is negligible $(<1.4 \%)$ for the observed range of $\delta^{13} \mathrm{C}$ values (-19\%o to $-30 \%$ ).

\subsection{Sensitivity Analysis}

Each of the variables in the model $\left(k_{D}, k_{S L}, h, s, f l u x 12 c T O T, f_{D}\right)$ was assigned an average value based on observations and previous studies (Boudreau, 1994; Sayles et al., 1994; Soetaert et al., 1996; Middelburg et al., 1997; Martin and Sayles, 2004) (Table 1). The sensitivity of the model to a particular variable was then determined by testing a range of expected/observed

215 values while holding all other variables constant at the assumed average value. Sensitivity is expressed as the absolute change in Fm for a given percent deviation from the assumed average value (Fig. 4a,b; electronic annex EA-4). The range for each parameter was chosen to provide full coverage of expected/observed values. For example, sedimentation rate (s), which varies over five orders of magnitude, is tested across a much wider range than the fraction of incoming

220 OC that is "degradable" $\left(f_{D}\right)$.

Our results suggest that modeled Fm values are most sensitive to sedimentation rate $(s)$ and mixed layer depth $(h)$. As expected, varying the sedimentation rate changes model sensitivity to mixed layer depth, and vice versa (Fig. 4b). Therefore, we confined our study to a subset of 75 cores (Subset 1; Fig. 1) for which sedimentation rate and mixed layer depth information was 225 available.

The same assumed average values of $k_{D}, k_{S L}$, flux12cTOT, and $f_{D}$ (see Table 1) are used for all samples because of the model's insensitivity to these variables (Fig. 4a). In fact, flux12cTOT (the total flux of OC to sediments) is a dummy variable that has no effect on 
modeled Fm values. Because Fm depends only on the ratio of ${ }^{14} \mathrm{C} /{ }^{12} \mathrm{C}$, the model simply requires

230 that we know how the ${ }^{14} \mathrm{C} /{ }^{12} \mathrm{C}$ ratio of the $\mathrm{OC}$ flux to sediments changes with time. We assume that each pool of OC in the sinking flux has the same ${ }^{14} \mathrm{C} /{ }^{12} \mathrm{C}$ ratio and that this ratio is defined by a single "generic" bomb curve derived from tropical W. Pacific corals (peak Fm at 1.12 in 1985) (Guilderson et al., 2004). While actual surface ocean DIC bomb curves exhibit regional variability in peak height and timing, they share a common shape. We tested the effect of using a 235 "generic" curve with a higher peak $(\mathrm{Fm}=1.16)$ derived from Florida corals (Druffel and Linick, 1978 ) and found that modeled Fm values increased on average by 0.0014 , which is much less than the average instrumental error associated with ${ }^{14} \mathrm{C}$ measurements. Under the conditions of a "generic" bomb curve and the assumed average values shown in Table 1 , bomb ${ }^{14} \mathrm{C}$ has a small but non-negligible effect on mixed layer OC (Fig. 5). Additionally, running the model with a 240 constant ${ }^{14} \mathrm{C} /{ }^{12} \mathrm{C}$ flux successfully replicated the steady state solution.

\subsection{Sedimentation Rates and Mixed Layer Depths}

The sedimentation rates and mixed layer depths used as model inputs were compiled from the literature or measured directly when corresponding sediment cores were available.

245 These data are available in EA-2 along with information about methods and references (EA-2 and EA-3). The majority of mixed layer depth estimates were derived from sediment profiles of unsupported ${ }^{210} \mathrm{~Pb}\left({ }^{210} \mathrm{~Pb}_{\mathrm{xs}}\right)$, while sedimentation rates were determined using gradients in the ${ }^{14} \mathrm{C}$ of foraminifera (or bulk $\mathrm{CaCO}_{3}$ ) in the mixed layer, TOC below the mixed layer, ${ }^{210} \mathrm{~Pb}_{\mathrm{xs}}$, or ${ }^{230} \mathrm{Th}$.

The radioisotopes ${ }^{210} \mathrm{~Pb}\left(\mathrm{t}_{1 / 2}=22.3 \mathrm{y}\right),{ }^{14} \mathrm{C}\left(\mathrm{t}_{1 / 2}=5730 \mathrm{y}\right)$, and ${ }^{230} \mathrm{Th}\left(\mathrm{t}_{1 / 2}=75,380 \mathrm{y}\right)$ decay at different rates, making each suitable for estimating mixing and sedimentation rates in 
specific depositional environments (Smith et al., 1993). ${ }^{230} \mathrm{Th}$ was used to determine sedimentation rates for slowly accumulating sediments of the abyssal Pacific (Druffel et al., 1984), while ${ }^{210} \mathrm{~Pb}$ was more appropriate at high accumulation $\left(>100 \mathrm{~cm} \mathrm{ky}^{-1}\right)$ shelf and slope 255 sites where mixed layer residence times are short $(<100 \mathrm{y})$. At sites with intermediate sedimentation rates, estimates can be highly sensitive to the choice of tracer. For example, in the Cascadia Basin ${ }^{210} \mathrm{~Pb}$-derived sedimentation rates exceed ${ }^{14} \mathrm{C}$-derived rates by two orders of magnitude (Hedges et al., 1999). At Station M off the coast of California the sedimentation rate was $28.4 \mathrm{~cm} \mathrm{ky}^{-1}$ using ${ }^{210} \mathrm{~Pb}$ (Cai et al., 1995) versus $1.36 \mathrm{~cm} \mathrm{ky}^{-1}$ with ${ }^{14} \mathrm{C}$ (Wang et al., 1998).

260 When run through our model, this difference in sedimentation rate translates into $\sim 0.3 \mathrm{Fm}$ units in ${ }^{14} \mathrm{C}_{\mathrm{TOC}}$, or more than 3000 radiocarbon years. In the case of Station $\mathrm{M}$ we use the ${ }^{14} \mathrm{C}$ sedimentation rate because the residence time of particles in the mixed layer $(5 \mathrm{~cm})$ is long on ${ }^{210} \mathrm{~Pb}$ timescales but short $(180-3700 \mathrm{y})$ relative to the half-life of ${ }^{14} \mathrm{C}$. The downside is that ${ }^{14} \mathrm{C}$ gradients below the mixed layer reflect sedimentation rates for some time in the past rather than 265 the present day. On the other hand, ${ }^{210} \mathrm{~Pb}$-derived sedimentation rates are almost always overestimates because of the effects of mixing.

For ten cores collected along the NW African margin we use ${ }^{210} \mathrm{~Pb}$ to estimate mixed layer depth. We assume that ${ }^{210} \mathrm{~Pb}_{\mathrm{xs}}$ decays much faster than it can be buried (at low sedimentation rate sites) and the presence of ${ }^{210} \mathrm{~Pb}_{\mathrm{xs}}$ below the sediment surface is primarily due 270 to downward mixing by benthic fauna. The mixed layer depth is therefore defined as the depth at which ${ }^{210} \mathrm{~Pb}_{\mathrm{xs}}$ is zero. We calculate Holocene sedimentation rates using planktonic foraminifera ${ }^{14} \mathrm{C}$ data provided by P. deMenocal at Lamont-Doherty Earth Observatory or available in the literature (see EA-2 and EA-3). At sites where foraminiferal data were unavailable, sedimentation rates were determined by ${ }^{14} \mathrm{C}_{\mathrm{TOC}}$ profiles below the mixed layer. We limit 
275 ourselves to Holocene records when possible since glacial cycles are known to change sedimentation rates (Mollenhauer et al., 2002).

\section{RESULTS AND DISCUSSION}

Fig. 2 shows a plot of the ${ }^{14} \mathrm{C}$ content (expressed as Fm) of TOC in surface sediments as a

280 function of water column depth. Three general features emerge from this plot. First, the greatest variability in Fm is apparent in sediments from water depths shallower than $1000 \mathrm{~m}$ (shelf and upper slope environments). These settings include sites with substantial quantities of aged carbon (small Fm values). Second, there is a general tendency for Fm values to decrease with increasing water depth along the young (right-side) edge of the distribution. The curved lines shown in Fig.

2852 represent a model of non-reactive OM, which defines mixed layer ${ }^{14} \mathrm{C}$ age simply as $h / s$, where $s$ decreases with depth (Middelburg et al., 1997) and $h$ is held constant at values (5 $\mathrm{cm}$ and 15 $\mathrm{cm})$ that bracket the global mean $(9.8 \mathrm{~cm}$; Boudreau, 1994). Finally, although the variability is greatest at shallow depths, substantial variability exists across all depths. Important information on OC source may be embedded within this variability.

290 We can begin to uncover factors controlling ${ }^{14} \mathrm{C}_{\mathrm{TOC}}$ variability in surface sediments by analyzing how observations and modeled values differ as a function of other geochemical properties. We reiterate that our model assumes that sedimentary OC is exclusively derived from contemporaneous marine production, which has the same radiocarbon content as surface ocean DIC. Thus, by excluding pre-aged OC inputs, our model results are intentionally biased toward 295 large Fm values and young radiocarbon ages.

\subsection{Comparing Measured and Modeled Core-top ${ }^{14} \mathrm{C}_{\text {TOC }}$ Content}


The sensitivity of our model to sedimentation rate and mixed layer depth require that we limit our comparative analyses to Subset 1 for which these parameters are well known. Our model overestimates the Fm value of surface sediments at $65 \%$ of sites, pointing to significant contributions of aged OC (Fig. 6). Discrepancies between modeled and measured values reflect both physical processes not considered by this simple model and some degree of uncertainty in model inputs. In general, sites where the model underestimates Fm are twice as sensitive to changes in sedimentation rate and mixed layer depth (Fig. 6). In other words, the average "error

305 bar" of a site below the 1:1 line is twice as large as that above the line, suggesting that Fm overestimates are generally less likely to be the result of inaccurate model inputs. These results lend support to the claim that Fm overestimates may reflect pre-aged OC inputs not considered by our model. The source and magnitude of this aged OC pool has important implications for models of OC cycling and burial in the oceans, as well as for the interpretation of sedimentary

\section{0 records.}

\subsubsection{Model Overestimates Fm}

There are a variety of reasons why our model would overestimate the Fm value of surface sediments. A primary reason mentioned above is that the model does not include a pre-aged OC input term. Therefore, if pre-aged inputs were important for a particular site, the model would

315 likely overestimate Fm. Sources of pre-aged OC can include reworked marine sediments, terrestrial OM that has aged in-transit to marine sediments, mobilized bedrock containing fossil (petrogenic) OC, methane gas hydrates, hydrocarbon seeps, combustion-derived black carbon, and anthropogenic petrochemicals.

Additional information can help us better characterize the mixture of pre-aged OC 320 sources at specific locations. Sediment grain size distributions and ${ }^{230} \mathrm{Th}_{\mathrm{xs}}$ have been used to 
identify sediment transport, winnowing, and focusing (Premuzic et al., 1982; Kienast et al., 2007; Broecker, 2008). Molecular-level biomarker analyses have also provided key insights into OC sources to marine sediments (Prahl et al., 1994; Eglinton et al., 1997; Pearson et al., 2000; Ohkouchi et al., 2002; Gordon and Goni, 2003; Drenzek et al., 2007). Both approaches may be

325 used in concert with our modeling approach to corroborate the presence of pre-aged carbon and constrain its origin at specific sites.

Anthropogenic disturbance of sediments via trawling and dredging operations could also lead to Fm overestimates in heavily fished areas on continental shelves due to enhanced sediment resuspension and direct mixing of deep, old sediments into the surface layer (Churchill, 1989;

330 Martin et al., 2008). Another alternative (discussed above in section 2.1.2) is that measured Fm is biased towards smaller values by aggressive inorganic carbon removal methods that may remove younger, more labile carbon (Komada et al., 2008).

\subsubsection{Model Underestimates Fm}

Underestimates of Fm may result from direct inputs of modern terrestrial OC with near-

335 atmospheric ${ }^{14} \mathrm{C}$ values, or as an artifact of measuring surface sediments (often the top few centimeters) while modeling the ${ }^{14} \mathrm{C}$ inventory of the entire mixed layer. Total organic carbon and ${ }^{14} \mathrm{C}_{\mathrm{TOC}}$ concentrations often decrease with depth in the sediment, reflecting degradation and a transition from high proportions of labile (young) organic matter to more refractory OM. Therefore, if the top $1 \mathrm{~cm}$ of sediment preferentially captures this labile material the sample will

340 return a higher Fm value than the modeled mixed layer depth integrated Fm.

Modeled Fm values are increasingly sensitive to changes in $s$ at low sedimentation rate sites (Fig. 4) where the majority of Fm underestimates exist (see below and Fig. 7c). Thus it is important to rule out systematic biases (related to tracer timescales, mixing, and methodology), 
especially at low accumulation sites. In general, small discrepancies between modeled and

345 measured ${ }^{14} \mathrm{C}_{\text {TOC }}$ ages can be resolved by adjusting model inputs (mainly $s, h$ ) within reported or expected ranges of uncertainty. Resolving the larger discrepancies may require additional OC input terms or alternative mechanistic explanations.

\subsubsection{Geochemical Properties and Patterns}

Discrepancies between modeled and measured Fm values (" $\Delta \mathrm{Fm}$ (modeled-measured)")

350 are plotted against six sediment characteristics in Fig. 7. When $\Delta \mathrm{Fm}$ is positive, the modeled Fm value exceeds the measured value (i.e., the measured ${ }^{14} \mathrm{C}_{\mathrm{TOC}}$ age is greater than the modeled age). There are correlations between $\Delta \mathrm{Fm}$ and water depth (Fig. 7a), $\delta^{13} \mathrm{C}_{\mathrm{TOC}}$ (Fig. 7b), sedimentation rate (Fig. 7c), and latitude (Fig. 7d), but no apparent relationships with mixedlayer depth (Fig. 7e) or \%TOC (Fig. 7f). Overestimates of Fm were common (i) at water depths

355 less than $2000 \mathrm{~m}$, (ii) when the $\delta^{13} \mathrm{C}_{\mathrm{TOC}}$ values were lower than $-20 \%$, (iii) at high $\mathrm{OM}$ accumulation sites $\left(s>0.05 \mathrm{~cm} \mathrm{y}^{-1}\right)$, and (iv) at intermediate to high latitudes, both in the northern and southern hemispheres (Fig. 7a - d).

The results for shallow water depths and near-shore high latitude sites suggest that proximity to continental sources may be an important determinant of mixed-layer sedimentary

360 OC. The trend toward increasingly positive $\Delta \mathrm{Fm}$ values at high latitudes may also reflect longer terrestrial OC residence times in these environments or a higher proportion of pre-aged terrestrial or petrogenic OC relative to marine OC. The fact that sites with highly depleted $\delta^{13} \mathrm{C}$ values also display positive $\Delta \mathrm{Fm}$ values suggests an important role for terrestrial $\mathrm{OC}$ in explaining the discrepancy between modeled and measured ${ }^{14} \mathrm{C}_{\mathrm{TOC}}$ content. The relationship between 365 sedimentation rate and $\Delta \mathrm{Fm}$ is also particularly strong, and we hypothesize that pre-aged OC 
inputs are in fact characteristic of high accumulation sites such as river-dominated margins, sediment drifts, and sediment depocenters (Ohkouchi et al., 2002; Mollenhauer et al., 2005).

\subsubsection{Sources of aged carbon}

Assuming the model is robust, then depending on the source(s) of aged carbon there are

370 different implications: (i) If the source of aged carbon stems from terrestrial biomass, then this has implications regarding the importance of marine sediments as a sink for $\mathrm{CO}_{2}$ removed from the atmosphere by terrestrial photosynthesis, as well as the temporal lag between carbon fixation on land and burial in the ocean; (ii) If the source is marine carbon that has aged through the processes of deposition, resuspension, and lateral transport, then this has consequences for

375 across-margin carbon transport, the role of margin-derived carbon in fueling benthic biogeochemical processes and carbon burial in the deep sea (Jahnke, 1996; Dunne et al., 2007), and our ability to interpret sedimentary records of past surface ocean properties; (iii) If the source is predominantly fossil carbon from bedrock erosion on adjacent hinterland, then (a) only a small amount of infinite age carbon is needed to change the measured ${ }^{14} \mathrm{C}$ age of TOC, and (b) 380 erosion and reburial of this petrogenic carbon has no net effect on atmospheric $\mathrm{CO}_{2} / \mathrm{O}_{2}$ (Galy et al., 2008); (iv) Finally, there is abundant evidence that anthropogenic inputs of fossil fuelderived carbon to the coastal ocean may be significant. These may take the form of combustion residues (black carbon), oil spills, organic materials synthesized from petrochemical feedstocks or other inputs (Griffith et al., 2009). Natural sources of fossil carbon emanating from the

385 seafloor may also be significant (e.g., petroleum or methane seeps) (Kvenvolden and Harbaugh, 1983; Hill et al., 2006; Pohlman et al., 2009).

\subsubsection{Gradients and Diagenesis}


Applying our database to issues related to OC cycling in the ocean depends on a better understanding of how diagenesis and sedimentological factors shape the character of

390 accumulating OC. In particular, since our model assumes a homogeneous mixed layer, it is necessary to evaluate possible biases due to the occurrence of concentration gradients in surface sediments. Mixed layer gradients in $\% \mathrm{TOC}$ and ${ }^{14} \mathrm{C}_{\mathrm{TOC}}$ can result from a combination of diagenetic and transport processes. On mixed layer timescales, microorganisms may gradually remove intermediate reactivity ("semi-labile") $\mathrm{OC}$. Additionally, subsurface maxima in ${ }^{210} \mathrm{~Pb}_{\mathrm{xs}}$,

$395 \%$ TOC, and ${ }^{14} \mathrm{C}_{\mathrm{TOC}}$ have been attributed to certain non-diffusive particle mixing processes such as "subductive" transport (Smith et al., 1997), which carries particles from the sediment surface to specific depth intervals below the surface. Finally, mixed layer ${ }^{14} \mathrm{C}_{\mathrm{TOC}}$ gradients may be attributable to the variable ${ }^{14} \mathrm{C}$ content of the flux to the sea floor over time. For example, bomb radiocarbon that was incorporated into semi-labile and refractory OC in sediments could 400 influence mixed layer gradients and provide a subject for future modeling studies.

\subsection{Comparing Depositional Settings}

Given the possible importance of sedimentation rate, mixed layer depth, and pre-aged organic matter inputs, we explored whether depositional setting might shed light on the

405 discrepancy between modeled and measured values.

\subsubsection{Open Ocean Sites}

Oxygenated open ocean sites are shown as orange circles in Figs. 6 and 7. Our model underestimates Fm for all of the open ocean sites except one at the Antarctic polar front. Together with enriched $\delta^{13} \mathrm{C}$ values (Fig. 7b Region I), this suggests that primarily fresh marine- 
410 derived OC inputs dominate at these sites. Yet, abyssal sites with particularly large negative $\Delta \mathrm{Fm}$ values may require additional explanation.

Take, for example, the N. Pacific site $(0-0.5 \mathrm{~cm} ; 5584 \mathrm{~m})$ with a reported sedimentation rate of $0.075 \mathrm{~cm} \mathrm{ky}^{-1}$ and mixed layer depth of $7.5 \mathrm{~cm}$ (Druffel et al., 1984). Our model underestimates the Fm of this core-top sample by nearly 0.3 units $(\sim 13,000$ years $)$. At first this is

415 surprising because our model assumes that flux to the sediments has a surface ocean ${ }^{14} \mathrm{C} /{ }^{12} \mathrm{C}$ ratio, meaning it should be biased towards modern values. The most reasonable explanation in this case is that there is a distribution of ages in the mixed layer and the uppermost sediments that were sampled are in fact much younger than the integrated mixed layer. This effect may be particularly severe for low accumulation sites with pronounced gradients through the upper

420 portion of the mixed layer. An alternate physical explanation could invoke large, direct inputs of "atmospheric" carbon (e.g. extremely fresh terrestrial OC), but this is extremely unlikely in the abyssal N. Pacific. It is possible that the sedimentation rate determined for this core (using ${ }^{230} \mathrm{Th} /{ }^{232} \mathrm{Th}$ ) was artificially low, resulting in a very old modeled age. In fact, moderate manipulations to mixed layer depth ( $27 \%$ decrease) and sedimentation rate (factor of 4 increase)

425 were sufficient to match the measured Fm. While our model is increasingly sensitive at low sedimentation rates (Fig. 4a,b), it is possible that biases due to mixed layer ${ }^{14} \mathrm{C}_{\mathrm{TOC}}$ gradients are especially large for abyssal sites where the sedimentation rate is low and the sampled core-top depth interval is small relative to the entire mixed layer depth.

\subsubsection{NW African Margin} The purple squares (Figs. 6 and 7) represent a group of NW African continental slope sites near the perennial upwelling regions of Cape Ghir and Cape Blanc (Helmke et al., 2005). This subset was chosen because we have a high degree of confidence in the sedimentation rate 
(based on foraminiferal ${ }^{14} \mathrm{C}_{\mathrm{CaCO}}$ ) and mixed layer depth (based on ${ }^{210} \mathrm{~Pb}_{\mathrm{xs}}$ ), which were measured on the same cores as ${ }^{14} \mathrm{C}_{\mathrm{TOC}}$. Karakas (2006) observed lateral offshore transport of 435 shelf sediments off Cape Blanc. Yet, for all but one of these sites our model underestimates the Fm of core-top OC, although to a lesser extent than the open ocean sites. The reasons for this are unclear, although they may be related to mixed layer ${ }^{14} \mathrm{C}_{\mathrm{TOC}}$ gradients, attenuation of young (labile) OC below the top centimeter of the mixed layer, direct eolian inputs from sources on the African continent, and/or rapid lateral transport of modern OC (see Mollenhauer et al., 2006;

$440 \quad$ Kusch et al., 2010).

\subsubsection{Peru and Benguela Upwelling Regions}

Sites from the upwelling regions off Peru and Namibia are shown as red diamonds (Figs. 6 and 7) and are characterized by high surface ocean primary productivity and exceptional OM preservation in underlying anoxic sediments (i.e. mixed layer depth $\sim 0 \mathrm{~cm}$ ). Enriched $\delta^{13} \mathrm{C}$

445 values point to OC sources derived from marine productivity. Remarkably, however, the model overestimates Fm for these surface sediments, suggesting that a significant fraction of the OC is pre-aged, possibly due to the resuspension and lateral transport of marine-derived OC (Fig. 7b Region II) (Mollenhauer et al., 2007).

\subsubsection{River-Dominated Washington Margin}

$450 \quad$ The green triangles (Figs. 6 and 7) correspond to a shelf-slope transect immediately offshore from the Columbia River. This subset was again chosen due to high confidence in the quality of the sedimentation rate and mixed layer depth information, and because it represents a river-dominated ocean margin. The model overestimates the Fm of surface sediments for all but one site in this subset, implicating pre-aged OC inputs. This subset is also characterized by

455 depleted $\delta^{13} \mathrm{C}_{\mathrm{TOC}}$ values (Fig. 7b Region III), suggestive of terrestrial and/or fossil OC 
contributions. It is notable that even within this very well characterized subset we find an outlier, where the measured $\mathrm{Fm}$ is significantly larger than predicted by the model $(\Delta \mathrm{Fm}=-0.32 ; \mathrm{Fig} .7)$. While this type of outlier reinforces the importance of interpreting each result in the appropriate regional context, it also highlights a potential strength of this approach in identifying specific

460 locations that do not conform to expected trends. These are sites where our modeled view of the world must adapt, and in doing so we may discover novel inputs and processes.

\subsection{Explaining Age - Water Depth Relationships}

At many sites, sedimentation rate and mixed layer depth are unavailable and costly to

465 obtain, which precludes using the model described here. Yet when combined with ancillary data, extensive measurements of ${ }^{14} \mathrm{C}_{\mathrm{TOC}}$ over a range of spatial scales have the potential to yield new information on OC source, transport, and preservation. This is illustrated by Fig. 8, which shows ${ }^{14} \mathrm{C}_{\mathrm{TOC}}$ content $(\mathrm{Fm})$ as a function of depth in three distinct continental margin settings (oxygenated open marine, river-dominated, and upwelling systems with associated oxygen 470 minimum zones).

Although these data are limited and exhibit considerable scatter, there appear to be differences in Fm-depth relationships. Perhaps surprisingly, sediments underlying the oxygen minimum zones off Namibia and Peru show the greatest decrease in Fm with increasing water depth, despite being characterized by rapid OC burial and dominated by organic matter derived

475 from marine productivity. Sedimentological information such as sedimentation rate and mixed layer depth would provide important insights on these patterns. For instance, decreasing Fm with water depth on the oxygenated and river-dominated margins could be explained by decreasing sedimentation rate in traversing from shelf to slope, and slope to basin (Middelburg et al., 1997). 
Differences in mixed layer depth or sedimentation rate need to be ruled out explicitly in

480 explaining the lower Fm values in the upwelling-dominated margins. However, it appears that a different explanation can be used to interpret these upwelling-margin data. Inthorn et al. (2006) suggest that lateral particle transport in bottom nepheloid layers is particularly important for the dispersal across highly productive continental margins such as the Benguelan upwelling system, and for enhanced accumulation of OC in slope sediments by maintaining elevated sedimentation

485 rates. Aging of particulate OC could occur through repeated cycles of deposition and remobilization into bottom nepheloid layers. Support for this process as a factor influencing core-top ${ }^{14} \mathrm{C}_{\mathrm{TOC}}$ content stems from comparisons of the ${ }^{14} \mathrm{C}$ age of specific algal biomarkers (alkenones) with co-occuring planktonic foraminiferal carbonate. Since the carbon in both of these types of organism stems from the surface ocean they should exhibit similar ${ }^{14} \mathrm{C}$ ages.

490 Discrepancies therefore imply an influence of pre-depositional processes. Mollenhauer et al. (2005) found a relationship between the magnitude of the alkenone-planktonic foram ${ }^{14} \mathrm{C}$ age difference and the OC content of the sediment, whereby alkenones exhibited the oldest ages relative to forams for sediments with the highest OC contents. For example, in slope depocenters on the margin underlying the Benguela upwelling zone the alkenones are as much as 4,000 $\mathrm{yr}$ 495 older than the foraminifera (Mollenhauer et al., 2003). As a result of continuous resuspension and the low settling velocities of OC in fluffy aggregates, the material could reside in the benthic boundary layer for extended periods of time while being laterally transported according to the flow conditions.

This example shows the power of combining data sets from different geographic regions, 500 applying the reasoning arising from a simple model incorporating diagenetic and sedimentological factors, and using the broadest possible range of ancillary data to aid 
interpretation. The creation of a global dataset and further refinement of the interpretive model described here may ultimately enhance our knowledge of OM source, pathways, and preservation on continental margins.

\section{CONCLUSIONS}

Results from this work suggest that the ${ }^{14} \mathrm{C}$ content of mixed layer OC adds important constraints on the sources of OM preserved in continental margins and on sedimentological processes. Our simple model of ${ }^{14} \mathrm{C}_{\mathrm{TOC}}$ of marine surface sediments was highly sensitive to

510 sedimentation rate and mixed layer depth. However, at several well-characterized sites, there were no reasonable combinations of sedimentation rate and mixed layer depth that would allow the model to match the measured ${ }^{14} \mathrm{C}_{\mathrm{TOC}}$ content of surface sediments. The model tended to return larger Fm values (younger ages) than actually observed. This finding provides strong evidence for inputs of pre-aged OC to the sediment surface at these sites. While it is tempting to

515 invoke this idea for all samples with overestimated Fm values, we have yet to resolve the effect of possible sampling biases and down-core concentration gradients. Nonetheless, if pre-aged inputs are driving the deviation between modeled and measured Fm, it may be possible to separately quantify the global burial of newly-formed and pre-aged carbon using our model deviations and estimates of OC burial at each of our sites.

520 In order to develop a predictive capability for the model that could be broadly applied, it will be important to link ${ }^{14} \mathrm{C}$ data to key depositional and water column properties or oceanographic regimes (e.g., Seiter et al., 2004) and expand our coverage of regions and water depths. Extending this approach to a larger suite of cores will require many additional measurements, or the use of global estimates for mixed layer depth (Boudreau, 1994) and 
525 sedimentation rate (Middelburg et al., 1997). Yet additional analyses would also help to validate the observed range of deviations between modeled and measured ${ }^{14} \mathrm{C}_{\mathrm{TOC}}$ content, and thus inform how far ${ }^{14} \mathrm{C}$ measurement precision could be reduced (thereby increasing sample throughput and decreasing cost) in this context. This information is important as ${ }^{14} \mathrm{C}$ measurement technology advances and our understanding of the global distribution of sedimentary ${ }^{14} \mathrm{C}_{\mathrm{TOC}}$ improves.

530 Acknowledgements. We thank M. Arthur, A. Burke, P. deMenocal, A. Dickens, E. Domack, N. Drenzek, M. Goñi, J. Goudreau, J. Hwang, R. Jahnke, L. Keigwin, A. Lima, R. Macdonald, N. McCave, A. McNichol, J. Moffett, G. Mollenhauer, D. Montluçon, N. Ohkouchi, A. Pearson, F. Prahl, C. Reddy, E. Roosen, J. Sachs, M. Uchida, T. Wagner, H. White, and M. Yunker, as well as the staff of the NOSAMS facility at Woods Hole Oceanographic Institution (WHOI), and the 535 captain and crew of the $R / V$ Oceanus. We also thank D. Burdige and two anonymous reviewers for their constructive comments on earlier versions of this manuscript. This work was supported by NSF grants OCE-0526389 (W. Martin), OCE-0851350 and OCE-0402533 (T. Eglinton), as well as WHOI Senior Scientist Chair and Independent Study Award funds (T. Eglinton). 


\section{REFERENCES}

Anderson R. F., Bopp R. F., Buesseler K. O., and Biscaye P. E. (1988) Mixing of particles and organic constituents in sediments from the continental shelf and slope off Cape Cod: SEEP-I results. Continental Shelf Research 8, 925-946.

Berner R. A. (1982) Burial of organic carbon and pyrite sulfur in the modern ocean - its geochemical and environmental significance. American Journal of Science 282, 451-473.

Blair N. E., Leithold E. L., Ford S. T., Peeler K. A., Holmes J. C., and Perkey D. W. (2003) The persistence of memory: The fate of ancient sedimentary organic carbon in a modern sedimentary system. Geochimica Et Cosmochimica Acta 67, 63-73.

Boudreau B. P. (1994) Is burial velocity a master parameter for bioturbation. Geochimica Et Cosmochimica Acta 58, 1243-1249.

Broecker W. (2008) Excess sediment Th-230: Transport along the sea floor or enhanced water column scavenging? Global Biogeochemical Cycles 22, GB1006.

555 Burdige D. J. (2005) Burial of terrestrial organic matter in marine sediments: A re-assessment. Global Biogeochemical Cycles 19, GB4011.

Burdige D. J. (2007) Preservation of organic matter in marine sediments: Controls, mechanisms, and an imbalance in sediment organic carbon budgets? Chemical Reviews 107, 467-485. 
Cai W. J., Reimers C. E., and Shaw T. (1995) Microelectrode Studies of Organic-Carbon Degradation and Calcite Dissolution at a California Continental Rise Site. Geochimica Et Cosmochimica Acta 59, 497-511.

Churchill J. H. (1989) The effect of commercial trawling on sediment resuspension and transport over the middle Atlantic bight continental shelf. Continental Shelf Research 9, 841-864.

Coppola L., Gustafsson O., Andersson P., Eglinton T. I., Uchida M., and Dickens A. F. (2007)

565 The importance of ultrafine particles as a control on the distribution of organic carbon in Washington Margin and Cascadia Basin sediments. Chemical Geology 243, 142-156.

Dickens A. F., Gelinas Y., Masiello C. A., Wakeham S., and Hedges J. I. (2004) Reburial of fossil organic carbon in marine sediments. Nature 427, 336-339.

Drenzek N. J., Montlucon D. B., Yunker M. B., Macdonald R. W., and Eglinton T. I. (2007) Constraints on the origin of sedimentary organic carbon in the Beaufort Sea from coupled molecular C-13 and C-14 measurements. Marine Chemistry 103, 146-162.

Drenzek N. J., Hughen K. A., Montlucon D. B., Southon J. R., dos Santos G. M., Druffel E. R. M., Giosan L., and Eglinton T. I. (2009) A new look at old carbon in active margin sediments. Geology 37, 239-242.

575 Druffel E. M. and Linick T. W. (1978) Radiocarbon in annual coral rings of Florida. Geophysical Research Letters 5, 913-916. 
Druffel E. R. M., Williams P. M., Livingston H. D., and Koide M. (1984) Variability of Natural and Bomb-Produced Radionuclide Distributions in Abyssal Red Clay Sediments. Earth and Planetary Science Letters 71, 205-214.

580 Dunne J. P., Sarmiento J. L., and Gnanadesikan A. (2007) A synthesis of global particle export from the surface ocean and cycling through the ocean interior and on the seafloor. Global Biogeochemical Cycles 21, GB4006.

Eglinton T. I. and Repeta D. J., (2003). Organic Matter in the Contemporary Ocean, Treatise on Geochemistry. Pergamon, Oxford.

585 Eglinton T. I., Benitez-Nelson B. C., Pearson A., McNichol A. P., Bauer J. E., and Druffel E. R. M. (1997) Variability in radiocarbon ages of individual organic compounds from marine sediments. Science 277, 796-799.

Eglinton T. I., Eglinton G., Dupont L., Sholkovitz E. R., Montlucon D., and Reddy C. M. (2002) Composition, age, and provenance of organic matter in NW African dust over the Atlantic Ocean. Geochemistry Geophysics Geosystems 3, 10.1029/2001GC000269.

Emerson S., Stump C., Grootes P. M., Stuiver M., Farwell G. W., and Schmidt F. H. (1987) Estimates of degradable organic carbon in deep-sea surface sediments from $14 \mathrm{C}$ concentrations. Nature 329, 51-53.

Galy V., Bouchez J., and France-Lanord C. (2007a) Determination of total organic carbon content and delta C-13 in carbonate-rich detrital sediments. Geostand. Geoanal. Res. 31, 199-207. 
Galy V., Beyssac O., France-Lanord C., and Eglinton T. (2008) Recycling of Graphite During Himalayan Erosion: A Geological Stabilization of Carbon in the Crust. Science 322, 943945.

600 Galy V., France-Lanord C., Beyssac O., Faure P., Kudrass H., and Palhol F. (2007b) Efficient organic carbon burial in the Bengal fan sustained by the Himalayan erosional system. Nature 450, 407-410.

Gearing P., Plucker F. E., and Parker P. L. (1977) Organic carbon stable isotope ratios of continental margin sediments. Marine Chemistry 5, 251-266.

605 Gordon E. S. and Goni M. A. (2003) Sources and distribution of terrigenous organic matter delivered by the Atchafalaya River to sediments in the northern Gulf of Mexico. Geochimica Et Cosmochimica Acta 67, 2359-2375.

Griffith D. R., Barnes R. T., and Raymond P. A. (2009) Inputs of Fossil Carbon from Wastewater Treatment Plants to US Rivers and Oceans. Environmental Science \& Technology 43, 5647-5651.

Guilderson T. P., Schrag D. P., and Cane M. A. (2004) Surface water mixing in the Solomon Sea as documented by a high-resolution coral C-14 record. Journal of Climate 17, 1147-1156.

Hartnett H. E., Keil R. G., Hedges J. I., and Devol A. H. (1998) Influence of oxygen exposure time on organic carbon preservation in continental margin sediments. Nature 391, 572615 574. 
Hedges J. I. and Keil R. G. (1995) Sedimentary organic matter preservation - an assessment and speculative synthesis. Marine Chemistry 49, 81-115.

Hedges J. I. and Oades J. M. (1997) Comparative organic geochemistries of soils and marine sediments. Organic Geochemistry 27, 319-361.

620 Hedges J. I., Keil R. G., and Benner R. (1997) What happens to terrestrial organic matter in the ocean? Organic Geochemistry 27, 195-212.

Hedges J. I., Hu F. S., Devol A. H., Hartnett H. E., Tsamakis E., and Keil R. G. (1999) Sedimentary organic matter preservation: A test for selective degradation under oxic conditions. American Journal of Science 299, 529-555.

625 Helmke P., Romero O., and Fischer G. (2005) Northwest African upwelling and its effect on offshore organic carbon export to the deep sea. Global Biogeochemical Cycles 19, GB4015.

Hill T. M., Kennett J. P., Valentine D. L., Yang Z., Reddy C. M., Nelson R. K., Behl R. J., Robert C., and Beaufort L. (2006) Climatically driven emissions of hydrocarbons from marine sediments during deglaciation. Proceedings of the National Academy of Sciences of the United States of America 103, 13570-13574.

Hwang J., Druffel E. R. M., and Komada T. (2005) Transport of organic carbon from the California coast to the slope region: A study of Delta C-14 and delta C-13 signatures of organic compound classes. Global Biogeochemical Cycles 19, GB2018. 
635 Inthorn M., Wagner T., Scheeder G., and Zabel M. (2006) Lateral transport controls distribution, quality, and burial of organic matter along continental slopes in high-productivity areas. Geology 34, 205-208.

Jahnke R. A. (1996) The global ocean flux of particulate organic carbon: Areal distribution and magnitude. Global Biogeochemical Cycles 10, 71-88.

640 Karakas G., Nowald N., Blaas M., Marchesiello P., Frickenhaus S., and Schlitzer R. (2006) High-resolution modeling of sediment erosion and particle transport across the northwest African shelf. Journal of Geophysical Research-Oceans 111, C06025.

Karlen I., Olsson I. U., Kallberg P., and Kilici S. (1968) Absolute determination of the activity of two 14C dating standards. Arkiv Geofysik 4, 465-471.

645 Kienast S. S., Kienast M., Mix A. C., Calvert S. E., and Francois R. (2007) Thorium-230 normalized particle flux and sediment focusing in the Panama Basin region during the last 30,000 years. Paleoceanography 22, PA2213.

Komada T., Anderson M. R., and Dorfmeier C. L. (2008) Carbonate removal from coastal sediments for the determination of organic carbon and its isotopic signatures, delta C-13 and Delta C-14: comparison of fumigation and direct acidification by hydrochloric acid. Limnol. Oceanogr. Meth. 6, 254-262.

Kusch S., Eglinton T., Mix A. C., and Mollenhauer G. (2010) Timescales of lateral sediment transport in the Panama Basin as revealed by radiocarbon ages of alkenones, total organic carbon and foraminifera. Earth and Planetary Science Letters 290, 340-350. 
655 Kvenvolden K. A. and Harbaugh J. W. (1983) Reassessment of the rates at which oil from natural sources enters the marine environment. Marine Environmental Research 10, 223243.

Lee C., Wakeham S., and Arnosti C. (2004) Particulate organic matter in the sea: The composition conundrum. Ambio 33, 565-575.

660 Lee C., Murray D. W., Barber R. T., Buesseler K. O., Dymond J., Hedges J. I., Honjo S., Manganini S. J., Marra J., Moser C., Peterson M. L., Prell W. L., Wakeham S. G., and Group A. S. C. F. (1998) Particulate organic carbon fluxes: compilation of results from the 1995 US JGOFS Arabian Sea Process Study. Deep-Sea Research Part II-Topical Studies in Oceanography 45, 2489-2501.

665 Lohse L., Helder W., Epping E. H. G., and Balzer W. (1998) Recycling of organic matter along a shelf-slope transect across the NW European Continental Margin (Goban Spur). Progress in Oceanography 42, 77-110.

Martin J., Puig P., Palanques A., Masque P., and Garcia-Orellana J. (2008) Effect of commercial trawling on the deep sedimentation in a Mediterranean submarine canyon. Marine Geology 252, 150-155.

Martin W. R. and Sayles F. L. (2004) Organic matter cycling in sediments of the continental margin in the northwest Atlantic Ocean. Deep-Sea Research Part I-Oceanographic Research Papers 51, 457-489.

Mayer L. M. (1994) Surface area control of organic carbon accumulation in continental shelf sediments. Geochimica Et Cosmochimica Acta 58, 1271-1284. 
Middelburg J. J. (1989) A simple rate model for organic matter decomposition in marine sediments. Geochimica Et Cosmochimica Acta 53, 1577-1581.

Middelburg J. J., Soetaert K., and Herman P. M. J. (1997) Empirical relationships for use in global diagenetic models. Deep-Sea Research Part I-Oceanographic Research Papers 44, 327-344.

Mollenhauer G., Schneider R. R., Muller P. J., Spiess V., and Wefer G. (2002) Glacial/interglacial variablity in the Benguela upwelling system: Spatial distribution and budgets of organic carbon accumulation. Global Biogeochemical Cycles 16, 1134-1148.

Mollenhauer G., McManus J. F., Benthien A., Muller P. J., and Eglinton T. I. (2006) Rapid lateral particle transport in the Argentine Basin: Molecular C-14 and Th-230(xs) evidence. Deep-Sea Research Part I-Oceanographic Research Papers 53, 1224-1243.

Mollenhauer G., Inthorn M., Vogt T., Zabel M., Damste J. S. S., and Eglinton T. I. (2007) Aging of marine organic matter during cross-shelf lateral transport in the Benguela upwelling system revealed by compound-specific radiocarbon dating. Geochemistry Geophysics Geosystems 8, Q09004.

Mollenhauer G., Eglinton T. I., Ohkuchi N., Schneider R. R., Muller P. J., Grootes P. M., and Rullkotter J. (2003) Asynchronous alkenone and foraminfera records from the Benguela Upwelling System. Geochimica Et Cosmochimica Acta 67, 2157-2171.

Mollenhauer G., Kienast M., Lamy F., Meggers H., Schneider R. R., Hayes J. M., and Eglinton 695 T. I. (2005) An evaluation of C-14 age relationships between co-occurring foraminifera, 
alkenones, and total organic carbon in continental margin sediments. Paleoceanography 20, PA1016.

Nagao S., Usui T., Yamamoto M., Minagawa M., Iwatsuki T., and Noda A. (2005) Combined use of delta $\mathrm{C}-14$ and delta $\mathrm{C}-13$ values to trace transportation and deposition processes of terrestrial particulate organic matter in coastal marine environments. Chemical Geology 218, 63-72.

Ohkouchi N., Eglinton T. I., and Hayes J. M. (2003) Radiocarbon dating of individual fatty acids as a tool for refining Antarctic margin sediment chronologies. Radiocarbon 45, 17-24.

Ohkouchi N., Eglinton T. I., Keigwin L. D., and Hayes J. M. (2002) Spatial and temporal offsets between proxy records in a sediment drift. Science 298, 1224-1227.

Pearson A., Eglinton T. I., and McNichol A. P. (2000) An organic tracer for surface ocean radiocarbon. Paleoceanography 15, 541-550.

Pohlman J. W., Bauer J. E., Canuel E. A., Grabowski K. S., Knies D. L., Mitchell C. S., Whiticar M. J., and Coffin R. B. (2009) Methane sources in gas hydrate-bearing cold seeps: Evidence from radiocarbon and stable isotopes. Marine Chemistry 115, 102-109.

Prahl F. G., Ertel J. R., Goni M. A., Sparrow M. A., and Eversmeyer B. (1994) Terrestrial organic carbon contributions to sediments on the Washington margin. Geochimica Et Cosmochimica Acta 58, 3035-3048. 
Premuzic E. T., Benkovitz C. M., Gaffney J. S., and Walsh J. J. (1982) The nature and distribution of organic matter in the surface sediments of world oceans and seas. Organic Geochemistry 4, 63-77.

Reimers C. E., Jahnke R. A., and McCorkle D. C. (1992) Carbon fluxes and burial rates over the continental slope and rise off central California with implications for the global carbon cycle. Global Biogeochemical Cycles 6, 199-224.

720 Ruttenberg K. C. and Goni M. A. (1997) Phosphorus distribution, C:N:P ratios, and delta C13(oc) in arctic, temperate, and tropical coastal sediments: Tools for characterizing bulk sedimentary organic matter. Marine Geology 139, 123-145.

Sayles F. L., Martin W. R., and Deuser W. G. (1994) Response of benthic oxygen demand to particulate organic carbon supply in the deep sea near Bermuda. Nature 371, 686-689.

725 Sayles F. L., Martin W. R., Chase Z., and Anderson R. F. (2001) Benthic remineralization and burial of biogenic $\mathrm{SiO} 2, \mathrm{CaCO} 3$, organic carbon, and detrital material in the Southern Ocean along a transect at 170 degrees West. Deep-Sea Research Part II-Topical Studies in Oceanography 48, 4323-4383.

Seiter K., Hensen C., Schroter E., and Zabel M. (2004) Organic carbon content in surface sediments - defining regional provinces. Deep-Sea Research Part I-Oceanographic Research Papers 51, 2001-2026.

Smith C. R., Pope R. H., Demaster D. J., and Magaard L. (1993) Age-Dependent Mixing of Deep-Sea Sediments. Geochimica Et Cosmochimica Acta 57, 1473-1488. 
Smith C. R., Berelson W., Demaster D. J., Dobbs F. C., Hammond D., Hoover D. J., Pope R. H., and Stephens M. (1997) Latitudinal variations in benthic processes in the abyssal equatorial Pacific: control by biogenic particle flux. Deep-Sea Research Part II-Topical Studies in Oceanography 44, 2295-2317.

Soetaert K., Herman P. M. J., and Middelburg J. J. (1996) A model of early diagenetic processes from the shelf to abyssal depths. Geochimica Et Cosmochimica Acta 60, 1019-1040.

740 Stuiver M. (1980) Workshop on C-14 data reporting. Radiocarbon 22, 964-966.

Stuiver M. and Polach H. A. (1977) Reporting of C-14 data - discussion. Radiocarbon 19, 355363.

Wang X. C. and Druffel E. R. M. (2001) Radiocarbon and stable carbon isotope compositions of organic compound classes in sediments from the NE Pacific and Southern Oceans.

$745 \quad$ Marine Chemistry 73, 65-81.

Wang X. C., Druffel E. R. M., Griffin S., Lee C., and Kashgarian M. (1998) Radiocarbon studies of organic compound classes in plankton and sediment of the northeastern Pacific Ocean. Geochimica Et Cosmochimica Acta 62, 1365-1378.

Westrich J. T. and Berner R. A. (1984) The role of sedimentary organic matter in bacterial sulfate reduction - the G model tested. Limnology and Oceanography 29, 236-249.

Zonneveld K. A. F., Versteegh G. J. M., Kasten S., Eglinton T. I., Emeis K. C., Huguet C., Koch B. P., de Lange G. J., de Leeuw J. W., Middelburg J. J., Mollenhauer G., Prahl F. G., Rethemeyer J., and Wakeham S. G. (2010) Selective preservation of organic matter in 
marine environments; processes and impact on the sedimentary record. Biogeosciences 7, 483-511. 


\section{Tables}

Table 1. Summary of Model Parameters

\begin{tabular}{ccccc}
\hline Parameter & Units & $\begin{array}{c}\text { Assumed } \\
\text { Average Value }^{*}\end{array}$ & $\begin{array}{c}\text { Unique Value } \\
\text { for Each Site? }\end{array}$ & Description \\
\hline$k_{D}$ & $\mathrm{y}^{-1}$ & 1 & $\mathrm{~N}$ & Rate constant for the "degradable" OC pool \\
$k_{S L}$ & $\mathrm{y}^{-1}$ & 0.04 & $\mathrm{~N}$ & Rate constant for the "semi-labile" OC pool \\
$k_{R}$ & $\mathrm{y}^{-1}$ & 0 & $\mathrm{~N}$ & Rate constant for the "refractory" OC pool \\
$h$ & $\mathrm{~cm}$ & 10 & $\mathrm{Y}$ & Mixed layer depth \\
$s$ & $\mathrm{~cm} \mathrm{y}^{-1}$ & 0.01 & $\mathrm{Y}$ & Sedimentation rate \\
flux12cTOT & $\mu \mathrm{mol} \mathrm{cm}^{-2} \mathrm{y}^{-1}$ & 40 & $\mathrm{~N}$ & Total OC flux to sediments \\
$f_{D}$ & - & 0.9 & $\mathrm{~N}$ & Fraction of the OC flux in the degradable pool \\
\hline 760 & * see text for references & & &
\end{tabular}




\section{Figure Legends}

Fig. 1. Map showing the location of 326 core-top ${ }^{14} \mathrm{C}_{\mathrm{TOC}}$ measurements (gray diamonds) as well

765 as 75 locations (Subset 1, red circles) where mixed layer depth and sedimentation rate are also well characterized.

Fig. 2. The ${ }^{14} \mathrm{C}$ content (measured as fraction modern, Fm) of TOC in surface sediments varies as a function of the depth of the overlying water column. Red circles indicate locations where

770 information on sediment accumulation rate and sediment mixed layer depth are available. The curved lines assume well-mixed, non-reactive OC with an age (and Fm value) defined by $h / s$, where $h$ is the mixed layer depth and $s$ is the sedimentation rate defined by Middelburg et al. (1997) as a function of water depth. Fm values of 1 correspond to a "modern" (1950) radiocarbon signature; the smallest Fm shown here corresponds to a radiocarbon age of 23,000

775 years. The average analytical error in Fm (0.0036) is smaller than the symbols.

Fig. 3. Model of OC in the sediment mixed layer used to predict the Fm of surface sediments. The incoming flux of $\mathrm{OC}$ has a ${ }^{14} \mathrm{C} /{ }^{12} \mathrm{C}$ ratio that varies with time according to a "generic" surface ocean DIC bomb curve. See section 2.2 for details.

Fig. 4. (a) The model is more sensitive to mixed layer depth $(h)$ and sedimentation rate $(s)$ than to OC degradation rate constants $\left(k_{D}, k_{S L}\right)$, the incoming OC flux (flux12cTOT), or the fraction of OC in the degradable pool $\left(f_{\mathrm{D}}\right.$; where $\left.\left(1-f_{\mathrm{D}}\right) / 2=f_{\mathrm{SL}}=f_{\mathrm{R}}\right)$. " $\Delta \mathrm{Fm}$ (modeled)" is the change in modeled Fm for a given percent change in the assumed average value (see Table 1); (b) As for 
785 (a) but showing how the choice of assumed average value changes model sensitivity to sedimentation rate and mixed layer depth.

Fig. 5. The effect of bomb radiocarbon on the ${ }^{14} \mathrm{C}$ content of mixed-layer organic matter through time as determined by the model described in section 2.2 and using the assumed average

790 parameter values given in Table 1. While the degradable OC fraction tracks the bomb curve closely, it is quickly degraded and therefore has little influence on mixed layer ${ }^{14} \mathrm{C}$. Refractory OC, with a residence time of 1000 years $(t=h / s)$, is not affected by bomb ${ }^{14} \mathrm{C}$, and its quantitative importance limits the total effect of bomb radiocarbon on the mixed layer. However, since the intermediate-reactivity fraction is significant, bomb ${ }^{14} \mathrm{C}$ has a small contribution to 795 mixed layer OC.

Fig. 6. Comparison of modeled and measured Fm for Subset 1. Several depositional settings are highlighted. They include a shelf-slope transect near the Columbia River (green triangles), a group of cores along the NW African continental margin (purple squares), upwelling regions off

800 of Peru and Namibia (red diamonds), and open ocean sites (orange circles). The 1:1 line is shown to indicate where modeled and measured values are equal. Error bars reflect the modeled response to a concurrent $10 \%$ increase (decrease) in sedimentation rate and $10 \%$ decrease (increase) in mixed layer depth.

805 Fig. 7. Discrepancies between modeled and measured Fm values as a function of (a) water depth, (b) $\delta^{13} \mathrm{C}_{\mathrm{TOC}}$, (c) sedimentation rate, (d) latitude, (e) mixed layer depth, and (f) \%TOC. Positive (negative) values of $\Delta \mathrm{Fm}$ (modeled-measured) indicate that the model has overestimated 
(underestimated) the actual Fm value. Depositional settings are highlighted by color and include a shelf-slope transect near the Columbia River (green triangles), a group of cores along the NW

810 African continental margin (purple squares), upwelling regions off of Peru and Namibia (red diamonds), and open ocean sites (orange circles). We hypothesize that Fm underestimates in Region I result from mixed layer OC gradients, while overestimates in Regions II and III reflect redistributed marine OC and pre-aged terrestrial/fossil OC respectively.

815 Fig. 8. The Fm of TOC in surface sediments varies as a function of water column depth for transects across oxygenated (NW Atlantic, black circles), river-dominated (NE Pacific Washington/Oregon, green triangles), and upwelling-dominated (Peru and Namibia, red diamonds) margins. Dashed lines are color coded for each margin system and are provided as visual aids only. They should not be interpreted as implying any functional relationships. Note 820 that these data points are a subset of those presented in Fig. 2. 


\section{Electronic Annex Captions}

EA-1. Full Database (326 sites, latitude, longitude, water depth, core depth, core type, fraction modern, reference)

825

EA-2. Subset 1 Database (75 sites, latitude, longitude, water depth, core depth, core type, \%TOC, $\delta^{13} \mathrm{C}_{\mathrm{TOC}}$, sedimentation rate $(s), s$ method, $s$ reference, mixed layer depth $(h), h$ method, $h$ reference, fraction modern, reference)

830 EA-3. Full citations for database references in electronic annexes EA-1 and EA-2

EA-4. Tabulated sensitivity analysis results. Each variable is analyzed across a range of reasonable/observed values while all others are held constant at the assumed average value (shown in bold and italics). These values are also displayed graphically in Fig. 4a. 


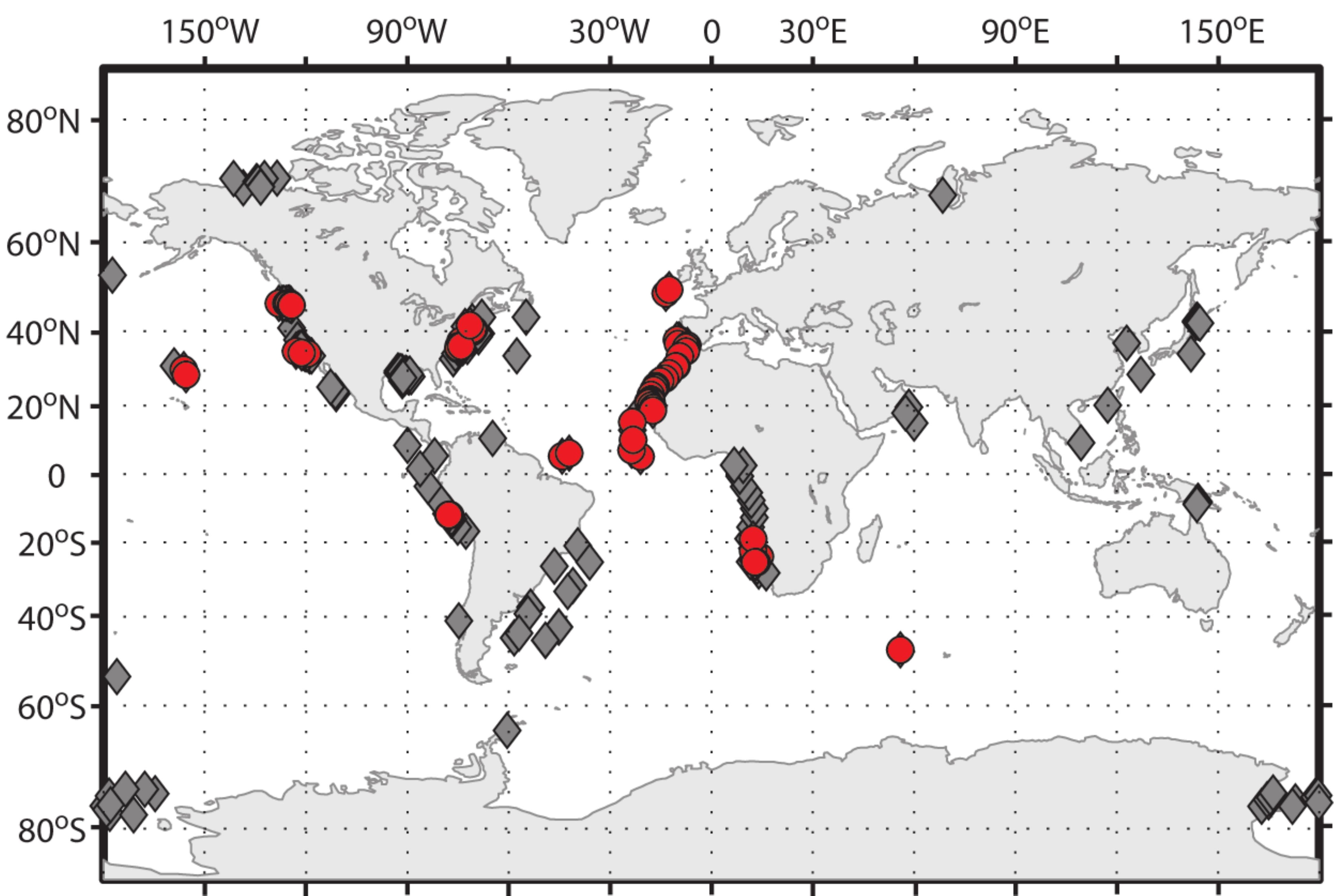




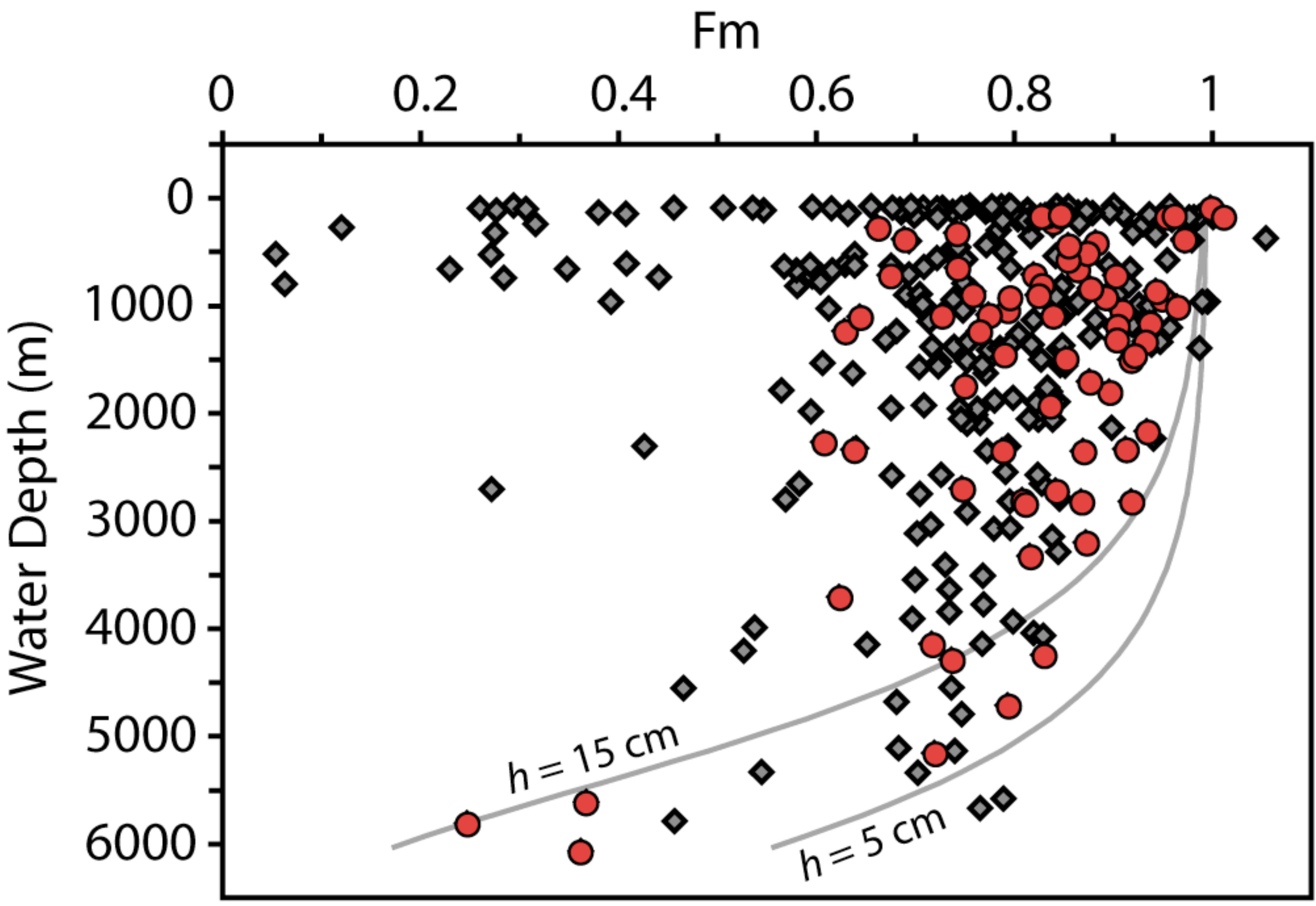


Input Flux of ${ }^{14} C_{O C}$ and ${ }^{12} C_{O C}$ "fluxTOT" ( $\mu \mathrm{mol} O C \mathrm{~cm}^{-2} \mathrm{y}^{-1}$ )

Radioactive Decay " $\lambda$ " $\left(\mathrm{y}^{-1}\right)$
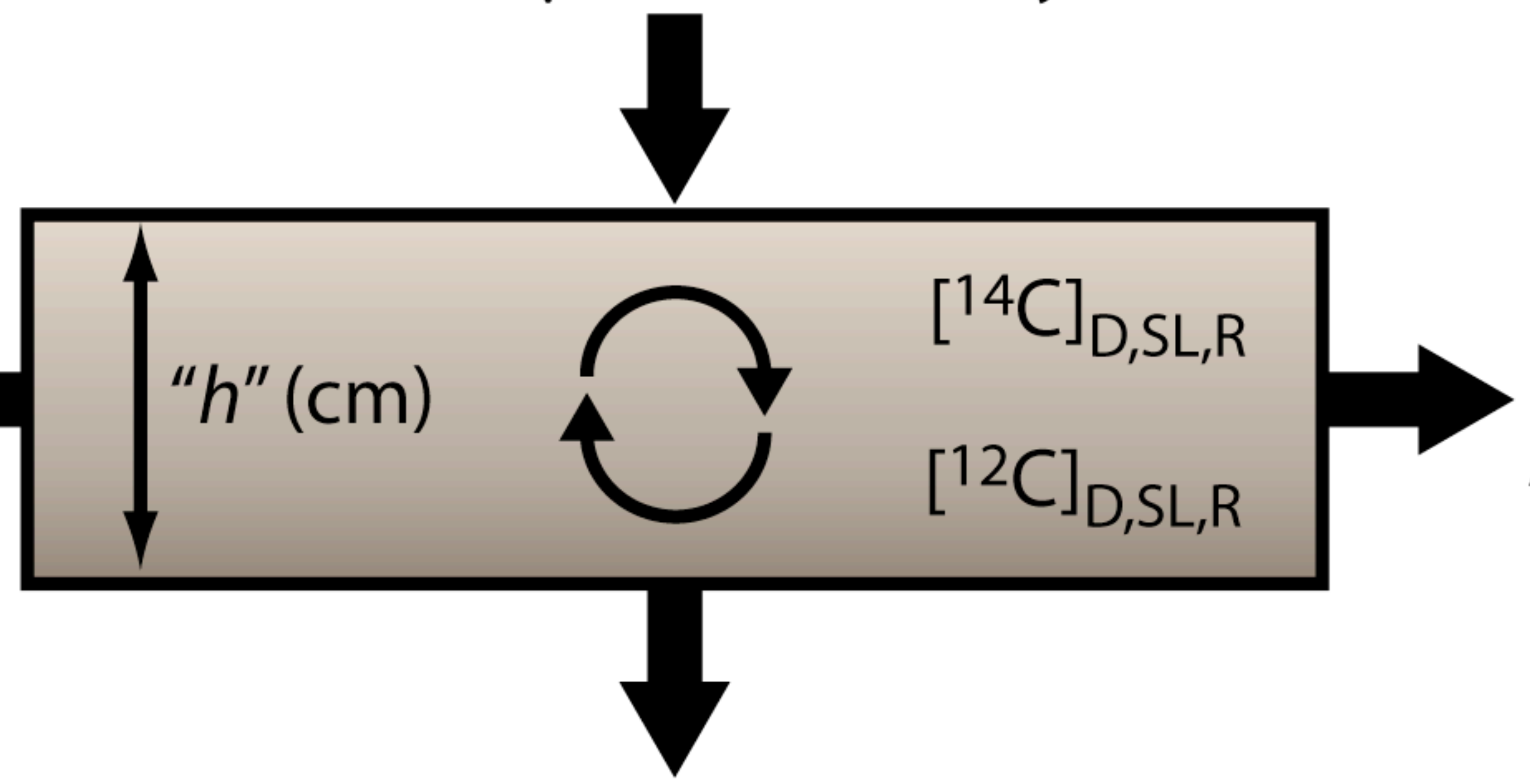

Oxidation Reactions "k $k_{D, S L, R}{ }^{\prime \prime}\left(\mathrm{y}^{-1}\right)$

\section{Burial or Sedimentation}

$$
\text { "s" }\left(\mathrm{cm} \mathrm{y}^{-1}\right)
$$



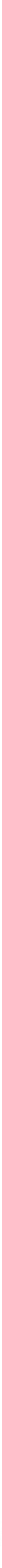

Percent change from assumed average value 


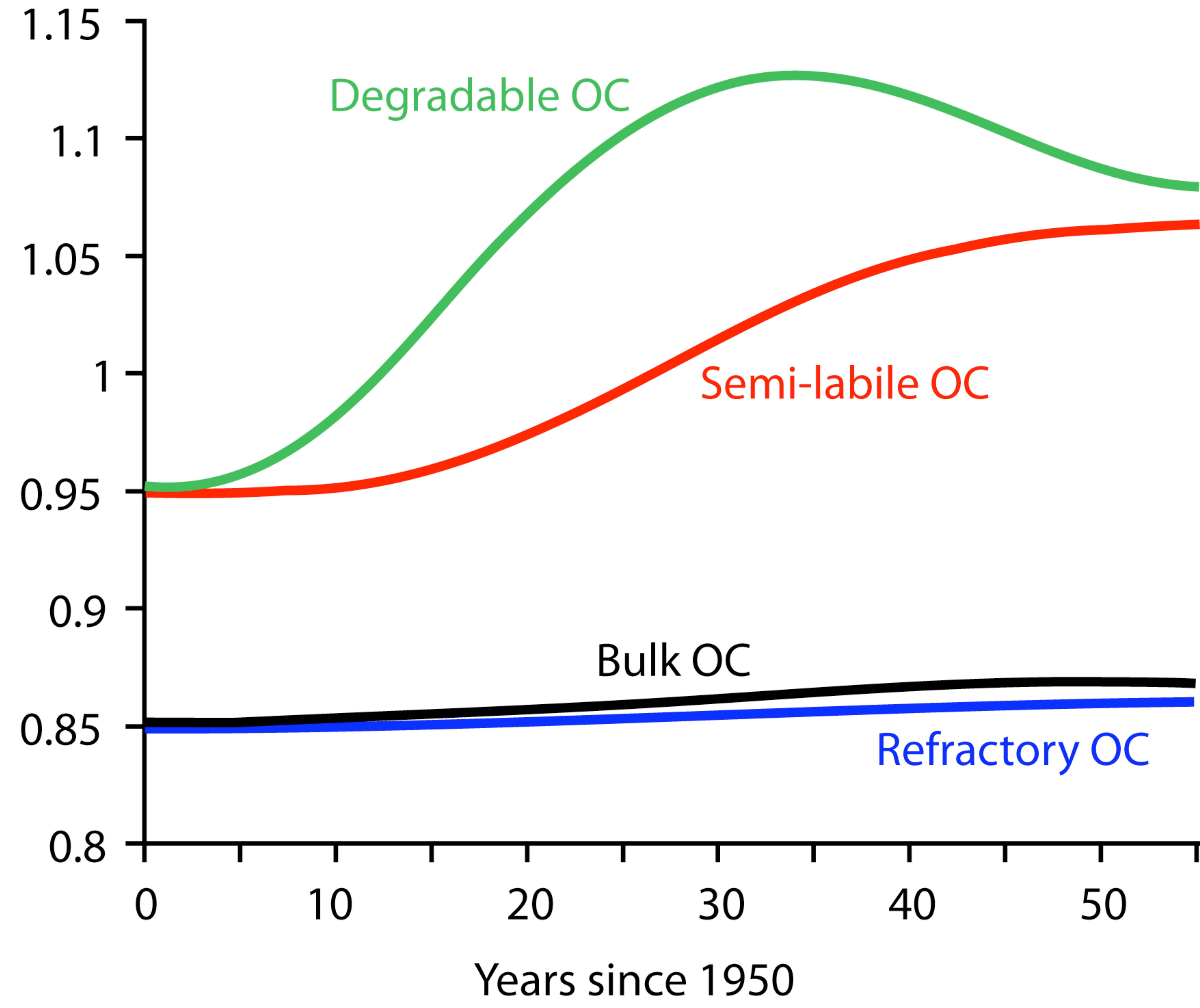




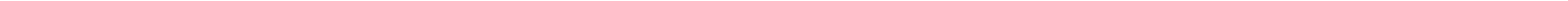


$\Delta \mathrm{Fm}$ (modeled-measured)

$\Delta \mathrm{Fm}$ (modeled-measured)
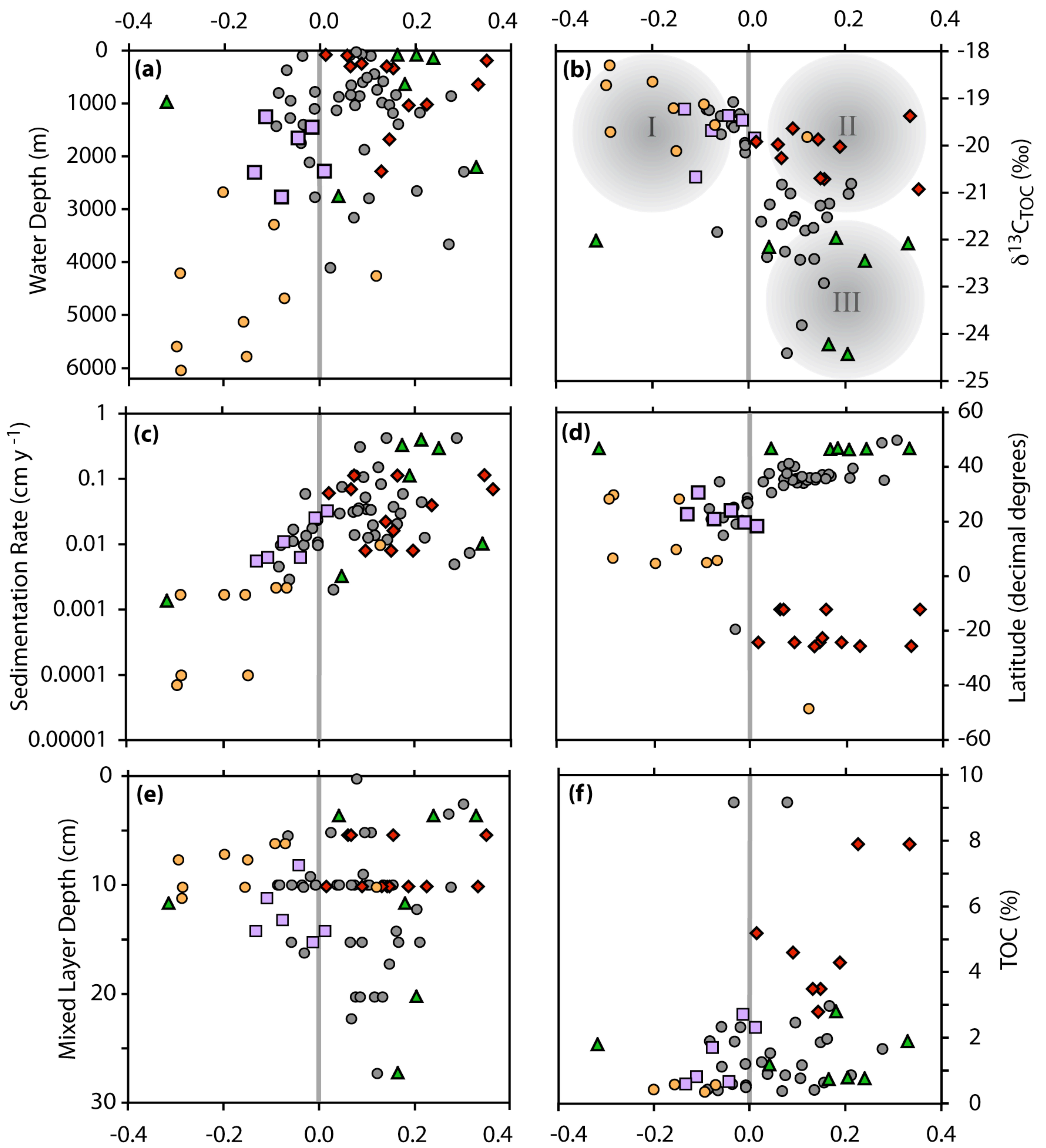
$\mathrm{Fm}$

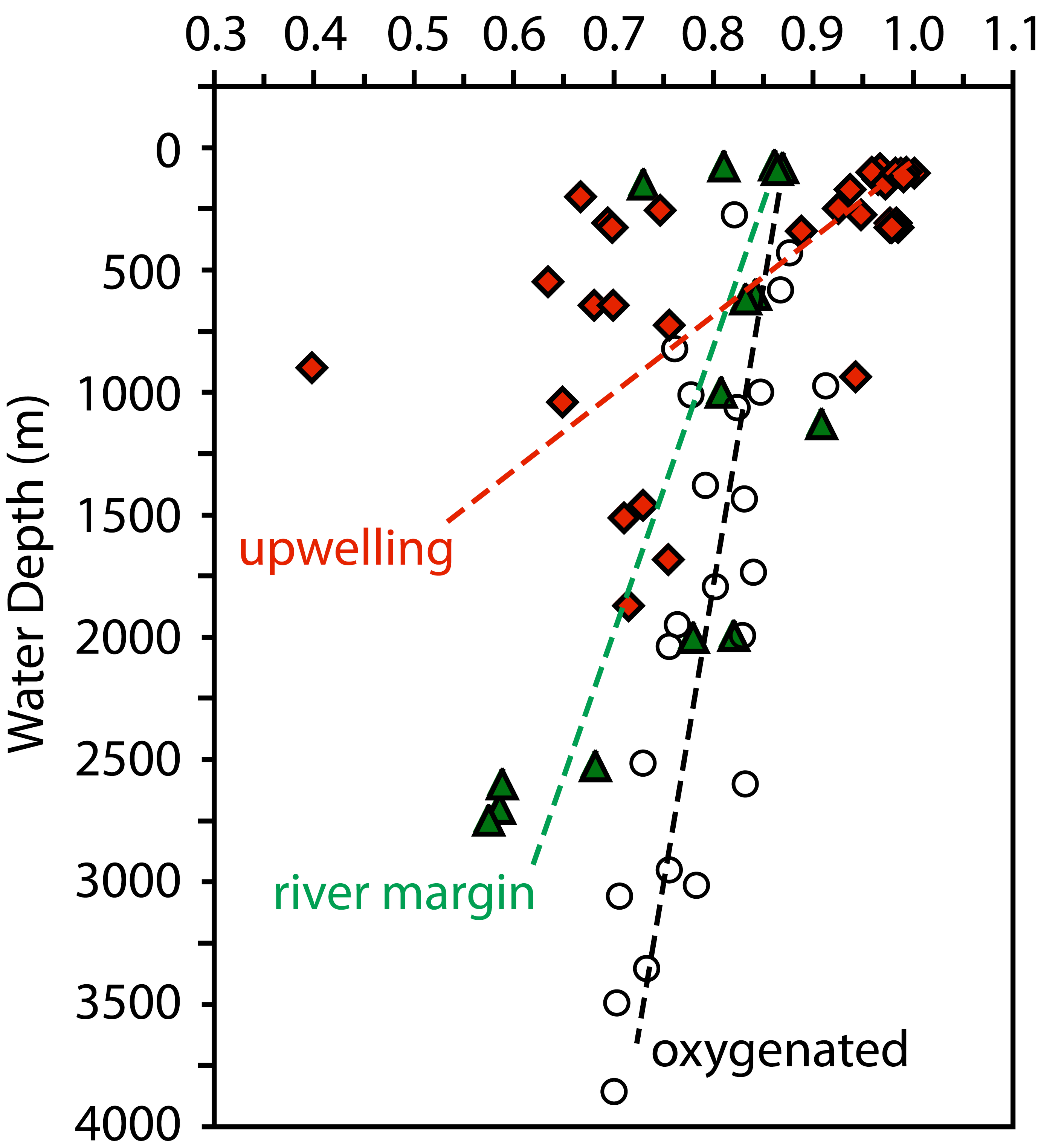

